\title{
Non-specific symptoms as clues to changes in emotional well-being
}

Andre Matalon ${ }^{1,2}$, Andy Kotliroff $^{1}$, Gari Blumberg ${ }^{1,3^{*}}$, John Yaphe ${ }^{4}$ and Eliezer Kitai ${ }^{1,3}$

\begin{abstract}
Background -: Somatic symptoms are a common reason for visits to the family physician. The aim of this study was to examine the relation between non-specific symptoms and changes in emotional well-being and the degree to which the physician considers the possibility of mental distress when faced with such patients.

Methods -: Patients who complained of two or more symptoms including headache, dizziness, fatigue or weakness, palpitations and sleep disorders over one year were identified from the medical records of a random sample of 45 primary care physicians. A control group matched for gender and age was selected from the same population. Emotional well-being was assessed using the MOS-SF 36 in both groups.

Results -: The study group and the control group each contained 110 patients. Completed MOS questionnaires were obtained from 92 patients, 48 patients with somatic symptoms and 44 controls. Sixty percent of the patients with somatic symptoms experienced decreased emotional well being compared to $25 \%$ in the control group $(p=$ 0.00005). Symptoms of dizziness, fatigue and sleep disturbances were significantly linked with mental health impairments. Primary care physicians identified only 6 of 29 patients (21\%) whose responses revealed functional limitations due to emotional problems as suffering from an emotional disorder and only 6 of 23 patients (26\%) with a lack of emotional well being were diagnosed with an emotional disorder.
\end{abstract}

Conclusions -: Non-specific somatic symptoms may be clues to changes in emotional well-being. Improved recognition and recording of mental distress among patients who complain of these symptoms may enable better follow up and treatment.

Keywords: somatic, non-specific symptoms, depression, anxiety

\section{Background}

Somatic symptoms are the main reason for visits to the family physician in primary-care clinics [1-5]. Often the visit yields no clear etiology or diagnosis that can explain the symptoms and the physician may describe it as "idiopathic," "atypical," "functional," or "non-specific" [3]. A broad study regarding symptoms in primary care [4] revealed that only $16 \%$ of the symptoms presented had a clear, organic etiology; for $74 \%$ no etiology was established over a three-year follow-up period, and the symptom remained the diagnosis. Frequently symptoms will pass without any treatment, and very often people

\footnotetext{
* Correspondence: gblumberg@leumit.co.il

'Department of Family Medicine, Faculty of Medicine, Tel-Aviv University, Ramat Aviv, 69978, Israel

Full list of author information is available at the end of the article
}

do not even consider visiting their physician when symptoms first appear.

Although not tied to a definite diagnosis, non-specific symptoms can interfere with patients' daily routine and be as detrimental to their quality of life as can organic and mental diseases that have been diagnosed unequivocally [5-8]. For example, decreased functioning from chronic fatigue is identical to that observed in patients with unbalanced hyperthyroidism or in those recovering from myocardial infarction [9].

Lasting non-specific somatic symptoms initiate a "journey of clarification." The co-travelers on this costly journey are the patient, who wants to know "what's wrong with me," and the physician, who wants to rule out treatable organic diseases. The journey includes repeated visits to primary care physicians, countless lab tests, many medications and other treatments, as well as 
referrals to a variety of specialists [10-12]. In addition, it is well known that mental stress, difficult life events and somatization, of course, can be experienced as somatic symptoms. At times, the symptoms can be the only expression of emotional distress or a psychiatric disease [13-15].

The two psychiatric diseases that family physicians most frequently encounter in the primary care clinic are depression and anxiety [16]. A Dutch study [17] looked at medically unexplained symptoms in the elderly and found a high rate of co-morbidity with anxiety and depression. Often these disorders are not diagnosed or treated [16,18-22] and cause reduced daily functioning and an over-use of health services. Frequently they present as somatic symptoms, and disregarding them may deepen their hold and harm doctor-patient relations [16].

The aim of this study was to examine the relation between non-specific symptoms and changes in emotional well-being such as depression and anxiety among patients consulting their primary care physician. The study also examined whether the clues of mental distress become stronger with an increase in the number of the non-specific symptoms and also the degree to which primary physicians consider mental distress when faced with a patient who complains of these symptoms. Our hypothesis was that multiple non-specific somatic symptoms are predictive of emotional distress, specifically anxiety and depression, and that this tends to be under-diagnosed by general practitioners.

\section{Methods}

This was a cross sectional survey, conducted in the community among individuals insured by one of Israel's four HMOs (health maintenance organizations). Patients were identified from the medical records and clues for anxiety and depression were assessed by a questionnaire at one point in time.

Data were derived from patients' medical files and from questionnaires. We obtained approval form the Research Regulation Committee of the HMO (Leumit Health Services) to use the data. Ethical approval for our study was granted by the Ethics Committee of Tel Aviv University.

\section{Research population}

This study, performed in 2002, examined the last 60 patient-doctor meetings (consultations) of a random sample of 45 physicians selected from among all the primary-care physicians in the HMO. Included were 15 general practitioners, 15 specialists in family medicine, and 15 internists. Data regarding the consultations were gathered using the computer program which the HMO uses for maintaining medical records.
A total of 2,700 medical consultations were examined. The patients were men and women, 20-70 years old. Patients with active cancer, dementia, congestive heart failure and those under psychiatric care or on dialysis were excluded from the sample. The symptoms noted were headache, dizziness, fatigue or weakness, palpitations and sleep problems. The research group consisted of 110 patients who complained of two or more of these symptoms at one visit or who complained of one symptom in more than two consultations within the year prior to the last meeting.

The control group consisted of individuals who were matched to each person in the research group for gender and age ( $+/-5$ years) and who had visited the same doctor on the same day, but did not have the symptoms of which the member of the research group complained.

\section{Research procedure}

The MOS-SF 36 Questionnaire, which measures patients' perception of their physical and mental health and social functioning, was used to assess the mental state of participants in both groups [23-25]. Two domains in the questionnaire which relate to emotional well-being and limitation of function due to emotional distress and which reflect the study hypothesis were selected as the outcome measures of this study. A previously validated Hebrew version of the questionnaire was mailed to the participants' homes [26] with an accompanying letter and stamped, self-addressed envelope for sending the replies to the HMO headquarters. A month after the questionnaires had been sent, those who had not yet returned them received a telephone reminder and a new questionnaire was mailed to them on request. One month later, another round of telephone calls was made to those who had not yet returned the questionnaires.

\section{Data processing}

Results were processed in accordance with the procedures detailed by Hays and Sherbourne in the MOS-SF 36 questionnaire [25] according to which a low score suggests that the patient suffers from a mental health problem. Patients whose score is lower than 50 on a 0 100 scale on questions of emotional well being and functional limitations due to emotional problems are at high risk for problems in these areas.

Statistics were calculated using BMDP Statistical Software (1993) and Epi-Info.

Correlation between each of the five symptoms and functional limitations due to emotional problems and emotional well being was assessed using the chi-squared statistic.

Correlation between the number of somatic symptoms of which the patient complained and functional 
limitation due to emotional problems and emotional well being was calculated using the chi squared statistic.

The chi squared test was also used to compare ratios between the research and control groups.

After retrieving from the questionnaires those patients who were at high risk to suffer from emotional problems or from lack of emotional well being, the researchers then checked to see whether the physician listed a mental health disorder as a possible diagnosis. The medical records of the patients in the control group were not examined to see if their physicians had later recorded mental health disorders.

Statistical significance was set at the level of $\mathrm{p}<0.05$.

\section{Results}

The researchers surveyed 2,700 consultations from the computerized medical records of 45 primary physicians. Of the total research consultations, 1,545 meetings were with women and 1,155 with men. The examination of these consultations yielded 110 patients who complained of functional somatic symptoms (Research Group), and 110 patients were matched to form the Control Group (see Methods).

The symptom that was most frequent among the 110 patients in the research group from the review of the electronic medical records was headache $(\mathrm{N}=32$, $29.1 \%)$, followed by fatigue ( $\mathrm{N}=29,26.3 \%)$ and dizziness $(\mathrm{N}=27,24.5 \%)$. Twenty patients in this group of $110(18.2 \%)$ had a single symptom. Complaints of two of the five symptoms were voiced by 46 patients (41.8\%), 32 patients (29\%) complained of three symptoms and twelve (10.9\%) of four while no patients complained of all five.

After telephone calls and repeated reminders, 92 completed MOS-SF 36 questionnaires were returned (41.8\%), of which 48 were from the research group (43.6\% of questionnaires sent) and 44 from the control group (40\% of questionnaires sent).

Of the remaining 128 questionnaires, 8 were returned by the postal service (addressee unknown), 17 arrived without demographic details, rendering them unusable, and 103 questionnaires were not returned at all. Table 1 presents the demographic characteristics of the study sample, showing no significant differences between responders in the cases and control group by age, gender, marital status or number of children.

Two domains from the MOS SF-36 questionnaire were addressed - functional limitations due to emotional problems and emotional well being. A score of 0 to 100 is possible. A lower score indicates more distress.

Table 2 presents the results of the questionnaire scores. Sixty percent of the patients in the research group suffered from lack of emotional well being (with a score less than 50), while in the control group the rate was $25.0 \%(p=0.00005)$. Forty five percent of the patients in the research group suffered from functional limitations due to emotional problems as compared to $43 \%$ of the patients in the control group ( $p=0.48$, n.s.).

The mean score for emotional well being was lower in the research group (a score of 42.3, as compared to the control group score of $76.1 ; p=0.0003$ ). There was no significant difference found in functional limitations due to emotional problems (mean score for cases 54.1; mean score in control group 55.6, $p=0.7$, n.s.).

Comparisons between the research and control groups with regard to functional limitations (MOS Score $<50$ for functional limitation) by individual symptoms are given in Table 3. There were no significant differences found regarding functional limitation when the two groups were compared by the presence of individual symptoms (headache, insomnia, dizziness, palpitations or fatigue).

Comparisons between the research and control groups with regard to a lack of emotional well-being (MOS Score $<50$ for emotional well-being) by individual symptoms are given in Table 4 . There were significant differences found between the proportion of patients with a lack of emotional well-being in the research group for four of the five symptoms studied (headache, insomnia, dizziness, and fatigue). There was no significant difference in emotional well-being for patients with palpitations compared to the control group.

Table 1 Demographic characteristics of the study population in the study of somatic symptoms and emotional well being $(\mathbf{n}=92)$

\begin{tabular}{|c|c|c|c|c|c|}
\hline \multirow[b]{2}{*}{ All respondents (\%) } & \multicolumn{2}{|c|}{ Research Group $(\mathrm{N}=110)$} & \multicolumn{3}{|c|}{ Control Group $(\mathrm{N}=110)$} \\
\hline & Total $=110$ & Responders $=48(43.6 \%)$ & Total $=110$ & Responders $=44(40 \%)$ & $\begin{array}{l}\text { Comparison of research } \\
\text { and control groups }\end{array}$ \\
\hline Number of women (\%) & $79(71.8)$ & $34(70.3)$ & $79(71.8)$ & $34(77.3)$ & $P=0.3, N S$ \\
\hline Number of men (\%) & $31(28.2)$ & $14(29.7)$ & $31(28.2)$ & $10(22.7)$ & $P=0.3, N S$ \\
\hline Mean age in years (range, s.d.) & $46.5(21-69)$ & $51.1(23-69,11.7)$ & $46.6(20-70)$ & $53.1(24-70,11.4)$ & $P=0.4, N S$ \\
\hline Marital status (\% married) & & $63 \%$ & & $62 \%$ & $P=0.8, N S$ \\
\hline Mean number of children & & 2.1 & & 2.3 & $P=0.7, N S$ \\
\hline
\end{tabular}


Table 2 MOS SF-36 scores for emotional well being and for limitation of function due to emotional distress for the research and control groups $(n=92)$

\begin{tabular}{|c|c|c|c|}
\hline & $\begin{array}{l}\text { Research group } \\
n=48\end{array}$ & $\begin{array}{l}\text { Control group } \\
\mathrm{n}=44\end{array}$ & \\
\hline Mean MOS score for emotional well-being (median, s.d.) & $42.3(33,44.9)$ & $76.1(100,39.5)$ & $P=0.0003$ \\
\hline \%of patients with impaired emotional well-being (MOS score $<50$ ) & $60 \%$ & $25 \%$ & $P<0.0005$ \\
\hline Mean MOS score for functional limitation due to emotional factors (median, s, d) & $54.1(56,22.0)$ & $55.6(58,22.0)$ & $P=0.7, N S$ \\
\hline $\begin{array}{l}\text { \% of patients with impaired functional limitation due to emotional factors (MOS score } \\
<50 \text { ) }\end{array}$ & $45 \%$ & $43 \%$ & $\begin{array}{l}P=0.48 \\
\text { NS }\end{array}$ \\
\hline
\end{tabular}

Among patients who complained of one symptom, $16.7 \%$ suffer limitations due to emotional problems. Among patients who complained of two symptoms, this rate is $60.0 \%$, which is significantly higher than the rate among those with one symptom $(p<0.05)$. Among the patients who reported one symptom the percentage of patients with low emotional well being was the lowest (33\%), and went up to $83.7 \%$ among patients with two symptoms $(\mathrm{p}<0.01)$. No correlation could be made between the number of symptoms greater than two and increased functional limitations or lack of emotional well being.

Finally, among patients whose responses revealed functional limitations due to emotional problems $(N=$ 29 - out of 48 total), only six (20.7\%) received a psychological diagnosis from their physicians: two were diagnosed with depression, two with anxiety, and two with stress. At the same time, among those patients whose responses revealed a lack of emotional well being $(N=$ $23)$, also six (26.1\%) received a mental diagnosis: two were diagnosed with depression, three with anxiety, and one with stress. The medical records of the patients in the control group were not examined to determine the prevalence of recording of mental health diagnoses so a comparison of rates between the two groups could not be made.

\section{Discussion}

Our research supports the hypothesis that patients who complain about nonspecific somatic symptoms suffer more from emotional distress, as seen by decreased emotional well being. It was surprising that such patients do not suffer significantly more from functional limitations due to emotional problems. Our study is a retrospective one which makes it difficult to ascertain whether the somatic symptoms cause the emotional distress or whether the opposite is true. As in most other studies on this subject, we can only say that there is a relationship but can not determine cause and effect.

As a tool for examining this relationship, we selected the MOS SF-36 Questionnaire, mostly for its "friendly" qualities in reference to a generally healthy population that sees a family physician for various reasons and its ability to assess a patient's functional state and health which has been proven reliable in previous studies [23-25].

The relationship between non-specific somatic symptoms, depression, and anxiety has been suggested in previous studies [2,16,27-29]. A perception of poor health, pain, or disability has been correlated with anxiety and depression symptoms in primary care patients [30]. $50 \%-80 \%$ of patients suffering from depression and anxiety first pay a visit to the family physician because of somatic complaints, without expressing any mental complaints [3,21,31,32]. Kroenke's work demonstrated that the rate of psychiatric disorders among patients who complain of somatic symptoms is at least twice as high as that in the general population of primary care clinic patients $[6,16]$.

Studies have tried to characterize the patients who come to a physician for somatic symptoms such as headache, fatigue, and gastrointestinal complaints as compared to those who do not turn to a physician when these symptoms appear $[33,34]$. Findings indicate that

Table 3 Comparisons between research and control groups with regard to presence of symptoms and functional limitations (MOS Score $<\mathbf{5 0}$ for functional limitation)

\begin{tabular}{lllll}
\hline complaint & N with complaint & \% with functional limitations & Statistical significance \\
\hline headache & 32 & Research group & Control group \\
\hline fatigue & 29 & 46.9 & 43.3 & $\mathrm{P}=0.45, \mathrm{NS}$ \\
\hline dizziness & 28 & 48.3 & 42.9 & $\mathrm{P}=0.39 \mathrm{NS}$ \\
\hline palpitations & 8 & 53 & 40 & $\mathrm{P}=0.17, \mathrm{NS}$ \\
\hline insomnia & 15 & 50 & 44 & $\mathrm{P}=0.51, \mathrm{NS}$ \\
\hline
\end{tabular}


Table 4 Comparisons between research and control groups with regard to presence of symptoms and lack of emotional well-being (MOS Score $<\mathbf{5 0}$ for emotional well-being)

\begin{tabular}{lllll}
\hline complaint & N with complaint & \% with lack of emotional well-being & Statistical significance \\
\hline headache & 32 & Research group & Control group & \\
\hline fatigue & 29 & 62.5 & 33.3 & $\mathrm{P}=0.0067$ \\
\hline dizziness & 28 & 65.5 & 33.3 & $\mathrm{P}=0.0038$ \\
\hline palpitations & 8 & 60.7 & 35.9 & $\mathrm{P}=0.024$ \\
\hline insomnia & 15 & 37.5 & 44 & $\mathrm{P}=0.51, \mathrm{NS}$ \\
\hline
\end{tabular}

those in the first group had suffered more stressful events throughout their lives, and were closer to meeting $D S M-I V$ criteria for anxiety disorders or depression disorders. It seems that stressful events increase the negative perception of symptoms. Dirkswager and Verhaak [35] found that patients with medically unexplained symptoms were more likely to have psychological distress, functional impairment and social isolation.

Certain somatic symptoms may serve as indicators of emotional distress, and their appearance alerts the physician in a more pronounced way than do others. Headache, insomnia, fatigue and dizziness were found in our research to be potential indicators of emotional distress. Kroenke et al. also described these symptoms as being strongly linked to depression and anxiety [2]. Sloane's survey, too, shows that dizziness is a very common symptom in the primary care clinic and in a large number of cases is related to psychiatric disorders [36]. Haug, et al, did a large study in Norway and found associations between depression, anxiety and certain somatic symptoms, including headache, nausea, heartburn, breathlessness, palpitations and trouble walking [37]. In our study, among patients who complained of dizziness, the rate of functional limitation due to emotional problems and lack of emotional well being was higher than the rate among patients without dizziness. In addition, we found that $66 \%$ of the patients who complained of fatigue suffered from functional limitations due to emotional problems, while this percentage was much lower among those without fatigue.

A larger number of somatic complaints is associated with a greater possibility that the patient has an emotional problem $[15,38]$. According to Kroenke [6] the risk of an emotional disorder in a patient visiting a primary clinic increases with the number of somatic symptoms of which he or she complains. Our research supports this, too; there is a significant difference between lack of emotional well being and functional limitations due to emotional problems in patients who report two or more somatic symptoms and between those who report just one.
Most primary physicians were trained with a biomedical orientation, in which the main purpose of the visit is to rule out organic disease [21]. This medical model often leaves mental etiologies as a "diagnosis of exclusion" [2]. Therefore, patients who have mental illness or emotional distress, and complain of somatic symptoms, are usually diagnosed later than those who report psychological or social symptom [22,31,32,39]. Similarly, our research revealed that the medical records of only $25 \%$ of patients with functional limitations due to emotional problems or lack of emotional well being contained a mental/emotional diagnosis. At the same time, it is likely that not every injury to emotional well being translates into a diagnosable mental/emotional or psychiatric disease. Another point to take into account is that the physician may be reluctant to write such a diagnosis in the file based on the first visit.

The study has some limitations. Even with a "friendly" questionnaire, one of the weaknesses of our research is the low $(41.8 \%)$ response rate, despite two telephone reminders. Nevertheless, this rate was close to that described in a broad study that examined the percentage of patients who responded to questionnaires and surveys in published research during the period 1985-1995 [40]. According to the study, only about $60 \%$ of patients respond to questionnaires mailed to them by their personal attending physician, and only about $50 \%$ respond to general surveys. Our questionnaire was sent to the patients from an unknown person, although with an accompanying letter from the HMO headquarters. There is also the possibility that some of the patients were not fluent in Hebrew or even illiterate as at least $20 \%$ of the HMO population is new immigrants to Israel. At the same time, the finding that the group of patients that returned the questionnaires is similar in all attributes to the group that did not return them does help to validate our data. A similar study was done in Scotland [41] using an electronic diary instead of questionnaires, but numbers were very small. Another limitation is the retrospective evaluation of symptoms. However, the work is strengthened by the use of a control group which is very similar to the research group. A 
further limitation was the lack of a review of the medical records of the patients in the control group for mental health diagnoses made during the follow-up year by the family physicians which would have allowed comparison with the research group.

\section{Conclusions}

We conclude by stating that because of the frequency of non-specific somatic symptoms seen by the primary care physician, and the possibility of a "hidden" mental disease or at least emotional distress accompanying them, it is the physician's duty to make use of every available clue in order to diagnose these conditions as early as possible. Our study shows that headache, fatigue, dizziness and insomnia are especially related to lack of emotional well being and to functional limitations due to emotional problems. Despite this, additional research is needed to examine the relation of these somatic symptoms to a diagnosis of depression and anxiety.

\section{Acknowledgements}

No one else except for the authors made significant contributions.

\section{Author details \\ ${ }^{1}$ Department of Family Medicine, Faculty of Medicine, Tel-Aviv University, Ramat Aviv, 69978, Israel. ²Department of Family Medicine, Clalit Health Services, Rabin Medical Center, Beilinson Hospital, Petach Tikva 49100 Israel. ${ }^{3}$ Department of Family Medicine, Leumit Health Services, 23 Shprintzak Street, Tel Aviv, Israel. ${ }^{4}$ Community Health, School of Health Sciences, University of Minho, Braga, Portugal.}

\section{Authors' contributions}

AM and EK conceived of the study. AM, AK and EK designed the study together. Data was collected by AK and EK and the analysis of the data was carried out by all five authors. Statistical analysis was performed by AK and JY. GB wrote the paper with help from AM, AK, JY and EK. All authors read and approved the final manuscript.

\section{Declaration of competing interests}

The authors declare that they have no competing interests.

Received: 17 August 2010 Accepted: 26 July 2011

Published: 26 July 2011

\section{References}

1. Kroenke K, Harris L: Symptoms Research: A Fertile Field. Annals of Internal Medicine 2001, 134:801-802.

2. Kroenke K, Price R: Symptoms in the Community. Archives of Internal Medicine 1995, 153:2474-2480.

3. Kroenke K: Studying Symptoms: Sampling and Measurement Issues. Annals of Internal Medicine 2001, 134:844-853.

4. Kroenke K: Common Symptoms in Ambulatory Care: Incidence, Evaluation, Therapy, and Outcome. The American Journal of Medicine 1989, 86:262-266.

5. Kroenke K: Symptoms in Medical Patients: An Untended Field. The American Journal of Medicine 1992, 92(supp. 1A):3S-6S.

6. Kroenke K, Spitzer RL, Williams JB: Physical symptoms in primary care. Predictors of psychiatric disorders and functional impairment. Archives of Family Medicine 1994, 3:774-9.

7. Servan-Schreiber D, Tabas G: Somatizing Patients: Part 2. Practical Management. American Family Physician 2000, 61:1423-8.
8. Duddu V, Husain N, Dickens C: Medically unexplained presentations and quality of life: a study of a predominantly South Asian primary care population in England. J Psychosom Res 2008, 65(4):311-7.

9. Kroenke K, Wood DR, Manggelsdorff : Chronic Fatigue in primary care: prevalence, patient characteristics, and outcome. JAMA 1988 260:929-940.

10. Barsky AJ, Borus JF: Somatization and medicalization in the era of managed care. JAMA 1995, 72:127-135.

11. Holloway $\mathrm{KL}$, Zerbe $\mathrm{KJ}$ : Simplified approach to somatization disorder. Postgraduate Medical Journal 2000, 108(6):89-95.

12. Jackson $J$, Kroenke K: Difficult Patient Encounters in Ambulatory Care. Archives of Internal Medicine 1999, 159:1069-75.

13. Smith GR, Monson R: Patients with Multiple Unexplained Symptoms. Archives of Internal Medicine 1986, 146:69-72.

14. Servan-Schreiber D, Tabas G: Somatizing Patients: Part 1. Practical Diagnosis. American Family Physician 2000, 61:1073-8.

15. Katon W, Sullivan M, Walker E: Medical symptoms without identified pathology: Relationship to psychiatric disorders, Childhood and adult trauma, and personality traits. Annals of Internal Medicine 2001, 134:917-925.

16. Kroenke K, Jackson JL, Chamberlin J: Depressive and Anxiety Disorders in Patients Presenting with Physical Complaints: Clinical Predictors and Outcome. The American Journal of Medicine 1997, 103:339-347.

17. Hilderink PH, Benraad CE, van Driel D, Buitelaar JK, Speckens AE, Olde Rikkert MG, Voshaar RC: Medically unexplained physical symptoms in elderly people: a pilot study of psychiatric geriatric characteristics. Am J Geriatr Psychiatry 2009, 17(12):1085-8.

18. Kressler D, Lloyd K, Lewis G, Gray D: Cross sectional study of symptoms attribution and recognition of depression and anxiety in primary care. BMJ 1999, 318:436-440

19. Schullberg HC, Burns BJ: Mental disorders in primary care: epidemiologic, diagnostic, and treatment research directions. General Hospital Psychiatry 1988, 10:79-87.

20. Kessler LG, Clearly PD, Burke JD: Psychiatric disorders in primary care: results of a follow up study. Archives of General Psychiatry 1988, 45:1100-1106.

21. Katon W, Kleinman A, Rosan G: Depression and Somatization: a review. The American Journal of Medicine 1982, 72:127-135.

22. Teng EJ, Chaison AD, Bailey SD, Hamilton JD, Dunn NJ: When anxiety symptoms masquerade as medical symptoms: what medical specialists know about panic disorder and available psychological treatments. J Clin Psychol Med Settings 2008, 15(4):314-21.

23. Brazier JE, Harper R: Validating the SF-36 health survey questionnaire: new outcome measure for primary care. BMJ 1992, 305:160-4.

24. Mc Horney CA, Ware JE, Rogers W: The validity and Relative Precision of MOS Short and Long Form Health Status Scales and Dartmouth COOP charts. Medical Care 1992, 30:253-265.

25. Hays RD, Sherbourne CD, Mazel RM: The Rand 36-Item Health Survey 1.0 Rand Health Sciences Program. Health Economics 1993, 2:217-227.

26. Lewin-Epstein N, Sagiv-Schifter T, Shabtai EL: Validation of the 36-item short-form Health Survey (Hebrew version) in the adult population of Israel. Medical Care 1988, 36:1361-70.

27. Whooley MA, Simon GE: Managing depression in medical outpatients. New England Journal of Medicine 2000, 343(26):1942-50.

28. El-Mallakh RS, Wright JC: Clues to depression in primary care practice. Postgraduate Medical Journal 1996, 100:91-8.

29. Nakao M, Yano E: Somatic symptoms for predicting depression: one-year follow-up study in annual health examinations. Psychiatry Clin Neurosci 2006, 60(2):219-25.

30. Wu LR, Parkerson GR: Health Perception, Pain, and Disability as Correlates of Anxiety and Depression symptoms in Primary Care Patients. The Journal of the American Board of Family Practice 2002, 15(5):183-190.

31. Bridges KW, Goldberg DP: Somatic presentation of DSM III psychiatric disorders in primary care. Journal of Psychosomatic Research 1985, 29:563-569.

32. Kirmayer $L$, Robbins JM, Dworkind M: Somatization and the recognition of depression and anxiety in primary care. The American Journal of Psychiatry 1993, 150:734-41.

33. Robbins PR, Meyersburg HA, Tanck RH: Interpersonal stress and physical complaints. Journal of Personality Assessment 1974, 38:578-85. 
34. Mechanic D: Effects of psychological distress on perceptions of physical health and use of medical and psychiatric facilities. Journal of Human Stress 1978, 4:26-32.

35. Dirkzwager AJE, Verhaak PFM: Patients with persistent medically unexplained symptoms in general practice: characteristics and quality of care. BMC Family Practice 2007, 8:33-42.

36. Sloane PD, Coeytaux RR: Dizziness. State of the Science. Annals of Internal Medicine 2001, 134:823-832.

37. Haug TH, Mykletun A, Dahl AA: The association between anxiety, depression and somatic symptoms in a large population: the HUNT-II study. Psychosomatic Medicine 2004, 66:845-851.

38. Spitzer RL, Williams JB, Kroenke K: Utility of a New Procedure for Diagnosing Mental Disorders in Primary Care- The Prime MD 1000 Study. JAMA 1994, 272(22):1749-1756.

39. Wilhelm KA, Finch AW, Davenport TA, Hickie IB: What can alert the general practitioner to people whose common mental health problems are unrecognized? MJA 2008, 188(12):S114-8.

40. Cummings SM, Savitz LA, Konrad TR: Reported response rates to mailed physician questionnaires. Health Services Research 2001, 35(6):1347-55.

41. Burton C, Weller D, Sharpe M: Functional somatic symptoms and psychological states: an electronic diary study. Psychosom Med 2009, 71(1):77-83.

\section{Pre-publication history}

The pre-publication history for this paper can be accessed here: http://www.biomedcentral.com/1471-2296/12/77/prepub

doi:10.1186/1471-2296-12-77

Cite this article as: Matalon et al:: Non-specific symptoms as clues to changes in emotional well-being. BMC Family Practice 2011 12:77.

\section{Submit your next manuscript to BioMed Central} and take full advantage of:

- Convenient online submission

- Thorough peer review

- No space constraints or color figure charges

- Immediate publication on acceptance

- Inclusion in PubMed, CAS, Scopus and Google Scholar

- Research which is freely available for redistribution

Submit your manuscript at www.biomedcentral.com/submit 